\title{
The Trend of Housing Defect on Newly Completed House
}

\author{
I. Ismail ${ }^{1}$, A.I. Che-Ani ${ }^{2}$, N.M. Tawil ${ }^{3}$, H. Yahaya ${ }^{4}$ \\ ${ }^{1,2,3,4}$ Department of Architecure, Faculty of Engineering \& Built Environment,Universiti Kebangsaan \\ Malaysia (UKM), Bangi 43600, Malaysia
}

\begin{abstract}
House as a shelter to everyone carries a very big impact form the economics point of view, since newly constructed houses have increased the price most rapidly. Thus, to parallel with the high price, the provision of a new house shall be free from any defects, even for the defects that people do normally consider as "cosmetic defects." This paper studies the trend of the building defects of a newly completed 72 units of a doublestorey terraced house. The building survey implemented consists of three steps of evaluation with the first stage by using Condition Survey Protocol 1 Matrix. This is done by the professional Surveyors, followed with pre-delivery inspection and customer inspection. As for new house, the survey work is very stringent in determining the defect's condition and priority. Survey and reporting procedure is carried out based on Condition Survey Protocol 1 Matrix and Multi Attribute Variable Technique. The result shows that for every stage of inspection, there is an improvement made on the housing condition. This means the repair work undertakes by the developer for every stage helps improved the house condition, before the handing over the process is being done from the developer to house buyers.
\end{abstract}

\section{Introduction}

House or its multiple form housing has remained the subject of research and discussion on a number of reputable platforms around the globe. The importance of housing has increased many folds and still is growing every-day pass. Housing is a basic need for all. The increased population and income will lead to the rapidly in housing demand. The increase of working group indirectly will increase the demand for houses since they are the productive group and have the purchasing power. Housing represents the largest investment in an individual life.

Developing countries are experiencing rapid industrial growth are striving hard to prevent themselves from being swallowed by the big economies. This trend by the underdeveloped nations results in unplanned growth, development and law transient in almost all walks of life, particularly in urban centers. Alarming rate of population growth is another problem faced by these countries which ultimately creates the demand for the increased number of housing facilities. In modern days, house is a basic icon of shelter where a man can plan to live and work under a protected environment. A case of building defects found in a newly completed house is not an unknown scenario in Malaysia. This does not mean that the new built houses should always be defect-free. In the theory of manufacturing, a defective product is going to happen, be it as good as the quality control process is applied. Such cases also apply to the construction industry. 
The acceptable construction product shall be determined as a standard of quality for new housing construction. Based on the standard, developer works should be accepted and the process of improving the construction quality should be continuing. Accordingly, this research was conducted as to assess the quality of a newly constructed house, whether or not it achieves the acceptable standard of housing quality.

\section{Literature Review}

By using a standard method, the building inspector can provide objective data regarding the status of the building for the property manager [1]. Quality indicators based on the condition of the building is a model that was developed to measure the performance and quality of the building. Previous research, BEPAS (a life cycle assessment models environmental performance assessment model) is related to the quality indicator. BEPAS is model-based life cycle assessment (LCA) for the first building in China [2].

In the meantime, many past studies related to defects in the building done in the postconstruction, which includes the operation and maintenance of buildings. However, few similar studies done in the design stage and during the construction phase. This study is focusing on the newly completed construction product as to support the concern of [3]. This is because defects in the building at the operational/maintenance to the building is influenced by the defects that occur during the construction process [3].

In Hong Kong, Tam et al. has reviewed the effectiveness of the Performance Assessment Scoring System (PASS) which was implemented by the authority in assessing the ability of Hong Kong contractors in managing the project according to the standards [4]. The system is seen as an effective evaluation and incentive system to encourage continuous quality improvement. However, analysis of PASS scores has shown that the quality of construction has not increased. Therefore, Tam et. al. [4] has recommended several steps to achieve continuous quality improvement in the construction of public housing.

Assessment of housing's condition is very important, and house-building segment of the construction industry is important [5] especially to meet the needs of the buyer. According to Crosby [6], the quality is to meet the requirements. The basis of a successful quality management system is a failure that repealed [7]. While quality is defined as the MS ISO 8402-1986 is the properties and characteristics of the whole of a product or service depends on the ability to meet the needs of the state, expressed or implied. In addition, a study conducted by Kazaz and Birgonul [8] to identify why the owner renovated their house found that they are not satisfied with the quality of their house and services provided in their house units.

Besides, the evaluation of housing condition is also important to ensure the health and safety to the occupants. Structural failure may result in loss of life and property damage [9]. According to Nurizan Yahya [10] the maintenance significantly influences the building safety and health of residents. Therefore, assessment of housing conditions is essential to obtain information related to carrying out maintenance work effectively. In addition, the quality of housing construction also reflects the image of the developer.

Building defects is the non-fulfillment of intended usage requirements [3]. Six common defects occurs in her research such as crack, moisture, peeling off, painting defect, rust and rot [11]. Generally 14 types of building defects such as leak, bend, rust, rot, moisture, sedimentation, crack and others [12]. There are some defects occur as the result of design errors, construction errors, and misuse of the buildings [12].

Based on analysis of concrete defect's factors in Malaysia, there are seven types of defects usually happen on the concrete structure such as crack, failed jointing, leaking, corrosion of steel reinforcement, sedimentation, honeycombed and disintegration of concrete. There are five main factors of concrete structure defects, which are design error, building material, geotechnique, construction errors and unpredicted errors [13]. 
This literature review suggests the need to perform the building condition survey, particularly to the newly completed construction product, as one of the methods in tracking the construction defects. This also helps the developers to identify and prioritize the most defected components in supporting the continuos quality improvement process.

\section{Methodology}

This research involves the evaluation on the newly completed 72 unit terraced houses. Building condition survey works has carried out using protocol 1 (visual inspection) techniques. The sample of the houses in this research is terraced houses located in housing area in Bandar Baru Bangi, Selangor.

The condition of building component is evaluated using a Standard Building Inspection Code published by the Royal Institutional of Surveyors Malaysia (RISM) and Condition Survey Protocol (CSP) 1 Matrix. This code and protocol are a guideline to the Building Surveyor to assess any defect of building based on priority and condition. This matrix has its own scoring system to facilitate the examiner to assess the condition of building carefully and entirety [14]. Another two stages is involving Multi Attribute Variables Technique (MAVT).

This researches are involved of three stages with the first stage was inspected by professionals and using the CSP1 matrix. In the second part, it involves the contractor to examine the building by using the five likert scale in determining the defects after that before the handover to the clients, after that in the final stage; it was rechecked again by the clients. All defects identified are assessed and recorded on-site with the evidence (photos and plan tag). The score obtained from the scoring system determine the level of defects/component such as good, fair and dilapidated. Furthermore, the possible cause of the defects also identified. This information recorded in Defect Sheet, and then it was compiled in the Schedule of Building Condition.

Findings from the three surveys are analyzed by using MAVT method even though the first has been conducted by using CSP1 matrix. The method of analysis transformed into MAVT for same standard of analysis. By this method, the number of defects, building defects score and rating for the buildings determined. The result from the research has been simplified in table form.

\section{Results and Analysis}

Bandar Baru Bangi is considered as new expanded township. Most of the houses build are terrace houses. Figure 1 shows the distribution of housing construction in Bandar Baru Bangi. This township covers an area of 1.869 hectares. It has developed in stages since 1974, with a target population of one hundred and twenty thousand people. Bandar Baru Bangi was conceived as an urban university town with the distribution of the property as in Figure 1.

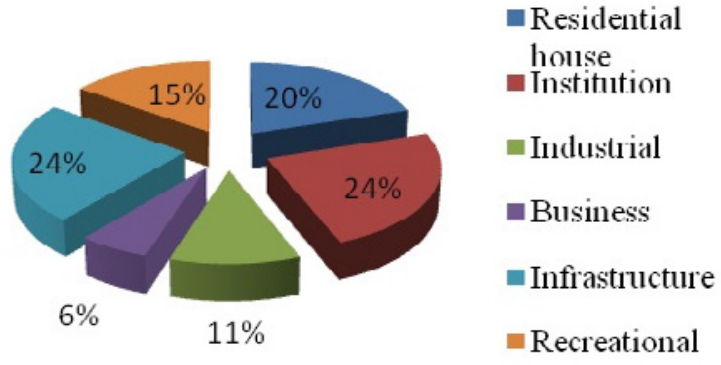

Figure 1: Distribution of the property developed in Bandar Baru Bangi

In conjunction with the Bandar Baru Bangi having several numbers of universities and training institutions for the district as well as a growth centre for the South Klang Valley, Bandar Baru Bangi developments are almost complete. Figure 1 show the distribution of property in Bandar Baru Bangi where institutions and infrastructure are $24 \%$ and $20 \%$ respectively, whereas business, recreational 
and industries are $6 \%, 15 \%$ and $11 \%$ respectively. This shows housing is among the main property developed in Bandar Baru Bangi. Thus, the condition assessment for newly completed house is at of importance.

Furthermore, building condition survey has been carried out on 72 units terraced houses. Overall, there are eight blocks of the houses and there are five types of house design. Figure 2 shows the result for each house in three stages of inspection. Based on Figure 2, it can be seen the first stage of evaluation has higher value of defects compared to the other two stages. We can see clearly the last stage done by the client or the owner has the least defect compared to the first two stages of condition assessment.

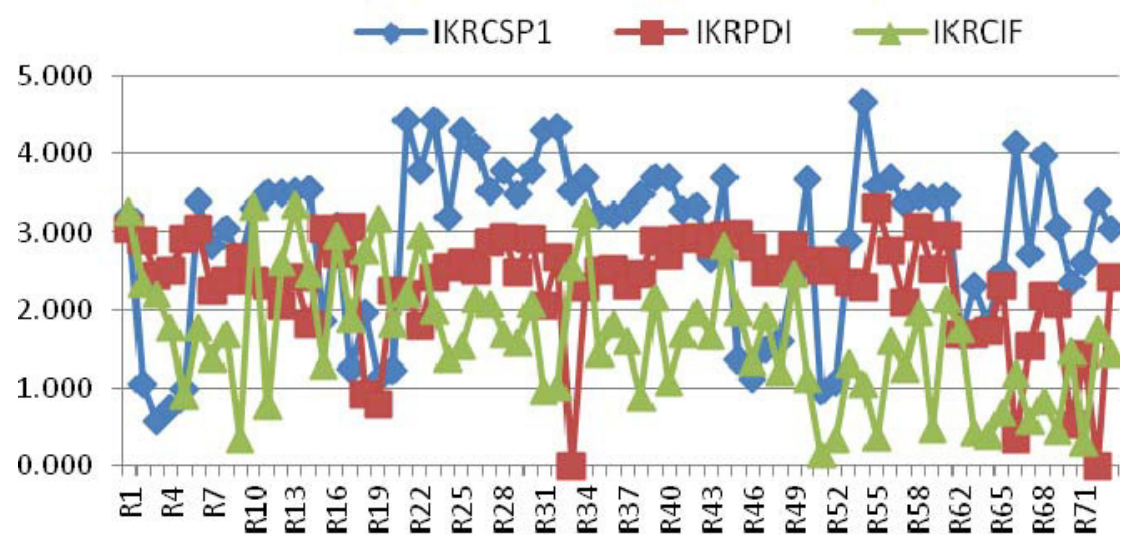

Figure 2: Trend analysis in examining three stages of the house defects

\subsection{The Percentage of Defects among Three Stages}

Based on Figure 3, after analyzing the Likert scale of these three stages, it is found that the defects found is significantly reduced in each phase of inspection. During the inspection phase of CSP1, 2,138 defects discovered and reported. However, after the corrective actions and PDI phase inspection performed, defects found defects decreased by 1,606 . Declining ability is $25 \%$. This shows a good improvement. When this entire defect has been identified and corrective actions have put in place, inspection phase of the CIF has found 817 defects. The decrease number of defects is encouraging, namely $49 \%$. This shows that in each phase of the examination when defects are discovered and reported, corrective action has been done properly and promptly. However, there are still categorized as minor defects found. This situation can be improved by providing a comprehensive action plan together with the standardization of the audit process before each inspection took place.

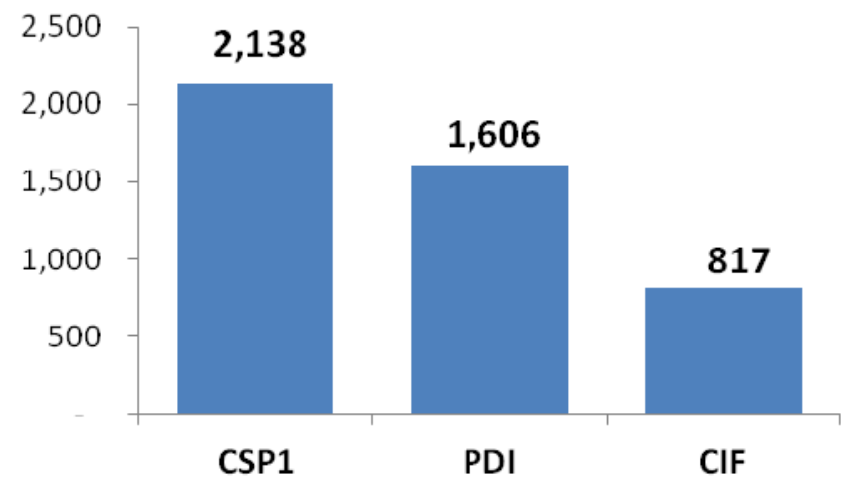

Figure 3: Numbers of defects from three stages of inspection 


\section{Discussion and Conclusions}

Along with the rapid development within the construction industry, particularly in residential construction, assessment of the quality of housing construction is very important to ensure that user requirements are met. In addition, the assessment of housing condition can also ensure the health and safety of consumers can be guaranteed. For the developer, the evaluation of housing conditions can help developers to maintain their works in order to give the good image of the developer.

The findings revealed that there are weaknesses in terms of construction works quality. The overall CSP1 Matrix rating for the houses is high; nevertheless, the numbers of defects are reduced in each next stage. If we refer to the first stage of CSP1 matrix, it shows that the houses are in dilapidated condition and requires serious attention. Besides, to meet user requirements for the new built houses, urgent maintenance work must be done to upgrade the condition of the houses. Hence, the second stage and the third stage show a lot of improvements thus overall construction needs to be viewed from all stage before the handling over to the clients.

\section{References}

1. Ad Straub. 2009. Dutch Standard for Condition Assessment of Building. Structural Survey. 27(1): 23-35.

2. Zhang, Z.H., Wu, X., Hui, X.M., Zhi, Y. 2004. BEPAS - A Life Cycle Building Environment Performances Assessment Model. Building and Environment. 41:669-675.

3. Josephon, P.E., Hammarlund, Y. 1999. The Causes and Costs of Defects in Construction: A Study of Seven Building Projects. Automation in Construction. 8: 681-687.

4. Tam, C.M., Deng, Z.M., Xeng S.X., Ho C.S. 2000. Performances of Assessment Scoring System for Public Housing Construction for Quality Improvement in Hong Kong (PASS). International Journal of Quality \& Reliability Management. 17(4/5):467-478.

5. Sommerville, J. 2007. Defects and Rework in New Build: An Analysis of the Phenomenon and Drivers. Structural Survey, 25(5):391-407.

6. Crosby, P.B. 1979. Quality is Free. New York: McGraw-Hill.

7. Juran, J. 1989. Leadership for Quality. An Executive Handbook. Free Press. New York.

8. Kazaz, A., Birgonul, M.T. 2005. The Evidence of Poor Quality in High-rise and Medium Rise Housing Unit: A Case Study of Mass Housing Projects in Turkey. Building and Environment. 40(11):1548-1556

9. Yuvabalan, G. 2005. Faktor-Faktor yang Mempengaruhi Penyenggaraan di Peringkat Rekabentuk. Dissertation. Universiti Teknologi Malaysia, Skudai.

10. Nurizan Yahaya. 1998. Kualiti Perumahan dan Kualiti Hidup. Analisis. 5 (1\&2):133-149. Reese, C.D. 2004. Office Building Safety and Health. CRC Press. Florida, USA. http://www.scribd.com/doc/53152787/Office-Building-Safety-and-Health.

11. Zuriani Md. Ali. 2003. Pengkelasan Kecacatan Bangunan Pada Bangunan Pangsapuri Kuarters Kerajaan Presint 9, Putrajaya. Prosiding Seminar Penyelidikan Jangka Pendek 2003. Universiti Malaya 11-12 Mac 2003. Paper No: 9.

12. Ahmad Ramly. 2004. Panduan Kerja-kerja Pemeriksaan Kecacatan Bangunan. Building \& Urban Development Institute. Selangor.

13. Mohd Zaki Mokhtar. 2006. Kerosakan dan Kemerosotan Struktur Konkrit di Malaysia. Dissertation. Universiti Teknologi Malaysia. Skudai.

14. Che-Ani, A.I., Tazilan, A.S.M., Kosman, K.A. 2011. The Development of a Condition Survey Protocol Matrix. Structural Survey. 29(1):35-45. 